\title{
The Research in Development and Strategy of Rare Earth Resource in Jiangxi
}

\author{
XuZhengHua \\ East China Institute of Technology College of \\ Economic and Management \\ East China Institute of Technology \\ Fuzhou City, Jiangxi Province, China
}

\author{
FuYing \\ Jiangxi University of Traditional Chinese Medicine \\ Nanchang City, Jiangxi Province, China
}

\begin{abstract}
Theuse of lonic rare earth resources pushesd evelopment of rare earth industry in Jiangxi, which plays an important role in economy of this province. However,some issues existin the process of developing rare earth metals,such as confusion duringe xploitation,disrupting the ecological environment,serious waste of resources, weakness in management and so on. Based on existing problems,this article focuses on a reasonable strategy in developing rare earth resources in Jiangxi.
\end{abstract}

Keywords-rare earth resources; exploitation and utilization;protectionof rare

\section{INTRODUCTION}

It was called"Industrial monosodium glutamate"and "The mother of new material", which is anon-renewable important rare earth resource. It is widely used in new resources andmaterials, saving energy, aerospace, and electrical information. In order to enact effective protection and reasonably use rare earth resources, it is very importantto protect the environment, quicken thedevelopment of new industries and promote rare earth industry sustainable development. After several yearsof development, we made great progress in exploitation, smelting separation and application technology research and development of rare earth resources. The scale of rare earth resources constantly expands. However, the rare earth industry still hassome serious problems, for example, long-standing illegal mining, damage of ecological environment, sheer wasting of resourcesand chaos in exporting. Jiangxi should pay more attention to the cognition of effective protection and reasonable utility in rare earth resources. Furthermore, it should adapt effective measures, strengthen management in the rare earth industry and promote rare earth industry sustainable development.

\section{DEVELOPING SituATIONOF IONICRARE-EARTH RESOURCES IN JIANGXI}

Abundant rare earth resources are mainly found in China, Australia, Russia, America, Brazil, Canada, and India. China has a good advantage in itsrare earth forming minercondition, a richness of ore types and its wide expansion but relative concentration. At present, geological workers found thousands of ore deposits, mines and mineralizing originsovertwo thirds of China. However, this oreis mostly concentrated inBaiyunebo in Inner Mongolia, Gannanin Jiangxi, Ebei in Guangdong, Liangshan in Sichuan and Weishan in Shandong. It forms a distribution pattern of north, south, west and east.Additionally,distribution characteristics focus more on the South.

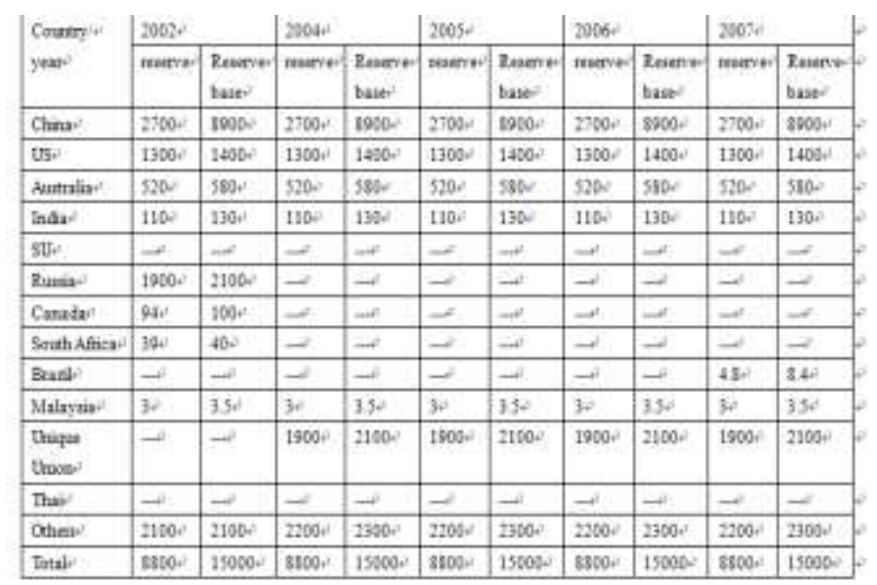

Figure 1. The reserve and reserve base of rare earth and other mining in the world(unit:ton)

Rare-earth resources can be divided into two main parts: heavy rare earth and light rare earth. Ionic type rareearth ore is the king of heavy rare earth in south of China, which is very valuable and always wanted by the West. This categoryincludes rare earth granite and comes from volcanic stone after yearsofweathering. The cover of the ore is shallow, andthe particles of the ore areloose and small. $80 \%$ $90 \%$ of rare earth element in the ore is on the surface of other clay ores, such as Kaolin, halloysite andhydromica, in ionic condition. Rare earth cations adsorbed on the clay minerals do not dissolve in water or ethanol, but in astrong electrolyte (such as the solution of $\mathrm{NaCl},(\mathrm{NH} 4)$ 2SO4, $\mathrm{NH} 4 \mathrm{Cl}$, NH4Ac, etc.), ions can exchange and enter the solution with a reversible reaction. In the late 1960s, ion absorption of heavy rare earth mines were found in Nanzu Cave in Jiangxi Province, and ion adsorption of rare earth mines in Xunwu River Ridge were also found. Since then, one after another has been found in southern China, including Fujian, Hunan, Guangdong, Guangxi, and more than 100 counties in seven provinces. The total reserve of ionic rare earth has been proven to be 1.6 million tons (REO) in the seven provinces. The evaluation predicts the E-class reserves will beapproximately 6.42 million tons (REO), total resource reserves will beapproximately 8 million tons[1] of rare earth metals.Prospective reserves are predicted to contain50 million tons, of which the heavy ion rare earth 
metals in Jiangxi province may compose up to 2.3 million tons, and the vision reserve is predicted to beup to 9.4 million tons, which ranks first in China. There is no doubt that Jiangxi province isvery rich inrare earthresources.

In the late 1980s, large-scale industrialized mining of ionic rare earth mining was stated in Jiangxi, thus Jiangxi was the first industrialized mining province in China. During 1970 1999, ionic rare earth mines were almost all using pool dipping technology, the utilization rate of which is $26 \%$. During 2000 2003, 50\% of the mining adopted In-situ leaching mining technology, which improved the utilization rate to $70 \%$ [2]. During 2004 2008, stack dipping technology and in-situ leaching mining technology were popular, and the utilization rate reached $75 \%$. At present, Jiangxi has more than 10 thousand tons / year, accounting for $60 \%$ to $70 \%$ of the amount of ion mineralof the rare earth mining capacity; investment in mining south ionic rare earth mine in all the private capital production business entities are the owners of artisanal miners. The overall scale of production capacity of more than $1000 \mathrm{t}$ (REO) single mine-scale production capacity very different scale in situ leaching scale capacity is generally in between the annual output of 100t and 500t (REO), the pool leaching capacity is generally an annual output of $10 \mathrm{t}$ $\sim 100 t$ (REO). Situ leaching exploitation of new technologies promote the use of a larger development, the Longnan all application Xunwu, Dingnan County are gradually expanding the range of applications, only a small number of mines still use the pool to dip or heap leaching.

\section{THE PRIMARY PROBLEM EXISTING IN THE}

\section{DEVELOPMENT AND USE OF JIANGXI'S ION-ABSORBING} TYPE RARE-EARTH NATURAL RESOURCES AND ITS CAUSE

In order to protect the precious,resource that is Ionabsorbing type rare earth metals and transforms this outstanding economic resource into an outstanding natural resource.For many years, Jiangxi hasenacted a series of control policies which have acquired definite results, but many problems in the development of rare-earth natural resources that influence sustainable development and environmental protection still exist.

\section{A. The Low Degree of Centralization in Rare-earth Manufacturing}

Data shows that in the 1990s, there were 4000 mining companies of all sizes, the large proportion of which were small companies. There are not many enterprise leaders in the rare-earth industry, and the effect of the spreading of radiation of the enterprise leaders is not large, which leaves us with no way of using them to form the scope of economic and manufacturing superiority. Before the year 2001, the primary rare-earth mineswerein Jiangsu (which had the bulk of the mines) and Guangdong companies. However, in the last 3 years, the rare-earth mining companies in Jiangxi achieved rapid expansion. The Jiangxi ionic rare-earth mining companies expanded rapidlyin the time period from 2005 to 2006, from the original ratio of one-third of the strength of the Jiangsu company to surpassing it in the first half of 2006. Due to the driving force of factions, Jiangxi rare-earth mining extractions are rather disorderly (counting illegal sites alone, there are more than 3,000 sites). Mine sites are not reasonably distributed; mining permits are not distributed according to a standard; both integrated and individual mine sites mine the land at random and dig excessively. In addition, the rate of natural resource use is relatively low; problems in companies' site construction appear repeatedly; there is disorderly competition, and efficiency if very low. This "small, scattered, careless, and poor quality" phenomenon has already become a disease in the Jiangxi rare-earth industry, not only leading to a waste of natural resources and confusion in the market, but also destroying the environment of the rare-earth source locations.

\section{B. the Wasting of Rare-earth Mineral Resources}

Against the background of the continuous increase of the price of rare-earth products and under the influence of profit, starting from the 80s, Jiangxi state run companies, mining teams, and private miners arose together. The rareearth mining and manufacturing companies of some places extract metals in a disorderly fashion, mine without permits, and mine across borders. Careless extraction and excessive digging was often seen, leading to the disorderly state of the development rare-earth natural resources. The "mine riches, relinquish poverty; mine ease, relinquish difficulty; leave out gas production, give up mineral resources, I phenomenon is very serious, and also has trends that continuously increase in intensity, and an ineffective rate of natural resource use. Also, this phenomenon is very wasteful, and consumes resources very quickly. For example, there is Longnan County in Jiangxi, a heavy rare-earth mining area. According to statistics, there are about 40,000 tons of high yttrium heavy rare-earth metals that can be mined by rare-earth mining industries. Using the yearly production scale of 4,500 tons and the use rate of $80 \%$ to calculate, there is only 7 years' worth of resources that can be mined.Bind production and the quickening of the overall increase in production have led to an excess of production power intense and vicious internal competition, an unbalance in the supply and demand of the rare-earth market, the slipping of rare-earth metal prices, drainage of soil and water at rare-earth production sites, and destruction of the ecology and environment at these places; all on a serious level.

\section{The Destruction of the Rare Earth Mineral Environment}

The Jiangxi ion absorption model of rare-earth metal ore mining primarily uses both outdoor reservoir immersion and local mining methods. The process of mining ionic rare earth metal ores gives rise to environmental problems, primarily those caused by the countryside reservoir immersion or the stack immersion method. These primarily include:

Destruction of Vegetation: Bringing minerals to the surface and distributing them, cutting down trees when mining, and peeling off the surface layer of soil all lead to serious destruction of vegetation wherever one performs these activities. They also result in abandonment of large areas, in fact changing the way the soil is used and changing the ecological processes of the local area.

Water and Soil Runoff: Ionic rare earth metal ore in the southern areas of Jiangxi is usually buried under granite that has been eroded by the wind. According to calculations, the reservoir immersion method destroys 200 
square meters of surface vegetation, strips 300 square meters of topsoil, produces 2000 cubic meters of tailings and topsoil waste for every ton of rare-earth metal mined. This leads to the production of 120 million cubic meters of water and soil runoff, pollution of the mine's environment, and destruction of the mine's ecology. The reservoir immersion method simultaneously produces a large amount of ammonium sulfate and heavy metal pollution, thereby greatly polluting the water source.

\section{The Rare-Earth Industry's Management Weakness}

We can see from the confusion of the rare-earth metal mine development in some places that Jiangxi's management of the development of the rare-earth mining industry is rather weak.

The Falling Apart of Command Plans and the Market: The Jiangxi rare-earth metal market has been using the model of the planned economy lead by the national plan for many years. This practice has been proven to be ineffective because the command plans and the market have fallen very far apart; the target and the actual result are also very different. Therefore using methods outside of the plan to mine and produce these metals became a must. For example, including Ganzhou, the southern portion of Jiangxi's command format rare-earth metal mining plans set forth the target of one ton per year. However, the production of oxides is 40,000 to 50,000 tons each year; the yearly planned and actual productions of rare-earth metal products differ by a large margin, causing the mining target to exist in name only.

Illegal Exports of Rare-earth Metals and Widespread Smuggling: As early as 1998, China had already imposed regulations on the export of rare-earth metal products. Following the daily expansion of the global need for rareearth metal products and the nation's continued decrease of the number of export companies on file as well as the export ration, some companies who received a rather large quota began to illegally speculate on quotas in order to gain profit. Furthermore, some developed nations, such as Japan, invested in establishing factories on sources of ionic rare earth metals on a large scale, heavily buying into rareearth and other uncommon metals at their locations of production, and, after simple processing, sending them to foreign countries to be further processed or stored, thereby successfully evading China's export quota regulations [3]. Meanwhile, rare-earth metal smuggling activity was becoming more rampant day by day. According to statistics, in the year 2009, rare-earth metals smuggled out of China will surpass 20,000 tons, making up one-third of the amount that leaves China.

\section{PRotective COUNTERMEASURES IN EXPLOITATION OF JIANGXI's RARE EARTH METAL RESOURCES.}

Since rare-earth metals are China's only precious natural resource, the related national ministries and commissions include Ionic rare-earth metals on the list of protected special mining types. The related ministries and areas of Jiangxi will create protective ionic rare earth metal exploitation plans, fair development of the science of ionic rare earth metal resources, and prevent the waste of resources, destruction of the ecology, and pollution of the environment.

\section{A. Promoting The Integration of the Rare-earth Industry}

Integrating the rare-earth metal industry is beneficial to protecting the environment and the precious rare earth natural resources. Currently, China's northern rare earth metal mining industry is basically integrated. China's largest rare-earth metal industry - the Inner Mongolia Baogang High-tech Joint-stock Limited Company (abbreviated as Baogang Rare Earth) is basically controlling northern China's light rare-earth. However, Southern China and Jiangxi's ionic rare-earth mining is rather distributed, and is confronted with improving its integration. The integration of the Jiangxi ionic rare-earth natural resources can adopt the following measures:

Using market strength and administrative methods: The government, through practical favorable taxation policies, increasing public capital investment, increasing the strength of economic support, and other such measures, will encourage large companies to use capital as the link. This will also encourage these companies to use the forming of alliances, annexation, reorganizing, and other such methods to voluntarily and independently participate in annexation. These companies will vigorously carry out rare earth natural resource integration, reducing the number of separate rare earth mining companies and metal smelting companies and improve the centralization of manufacturing. The implementing of rare earth industries annexing and re-organization will follow an overall plan, be guided by policy, market operations, balance central, local, and company benefits, and properly handle the relationship between differing areas and upper and lower travel industries.

Legal Methods: Long term regulations on the integration and mining of rare-earth natural resources will be implemented. Although market and administrative methods are important, the effective tool of law must still be put to use. In the process of cleaning up the messy rareearth situation, the competition between interest groups will be intense. The department with the right to integrate the resources must act in light of interrelated laws.

The rare earth resources that belong to the country must be clarified: There are departments of regional people's governments with a function that does not belong to the locality of the resources and populations or companies with a mining warrant that are also not of the locality of the resources. The country's authority to dispose of, manage, receive profit from, and determine policy related to rare-earth natural resource mining will be regulated.The law must be strictly adhered to punish illegal mining.

Through the above measures, the Jiangxi province can work hard to form the basics of this company-led rareearth industry pattern. The top three companies in the ionic rare-earth industry have group industry separation of $80 \%$ or higher.

\section{A. The Order of Developing Rare-earth Integration}

Going along with the current disorderly situation of ionic rare-earth manufacturing and mining locations, the related departments of the Jiangxi government should adopt firm measures, strengthen the management, and specify and develop rare-earth development.

$$
\text { 1) firm restraint of illegal mining: }
$$


a) the distribution of the organizational responsibility must be strengthened. With the group that crated the rare-earth mining centralization survey, divided into the management bureau, the forest industry bureau, the public safety bureau, the national land bureau, the water protection bureau, the environmental protection bureau, the safety supervisory bureau and other such units, taking the lead with this responsibility, every work group will send one or two mining management level workers, three to four township employees (one or two to conduct a survey).

b) Patrol of the development must be strengthened. Every related department must further increase its patrols of each rare-earth natural resource area within itsadministrative region, strengthen the patrol of already discovered illegal mining activity, discover illegal activity, report it, and stop it earlier in a practical manner.

c) Strengtheningcrackdown on illegal activities: The related departments, using a concentrated effort and based on the discovery of illegal rare-earth mining sites by the patrols will adopt measures, implement centralization, and resolutely stop illegal activity.

d) An administrative accountability system will be established. Establish a "worker "responsibility system to ensure the orderly development of the rare-earth integration system. This system will not doing one's best in investigating the related leaders' responsibilities in watching for illegal mining activity, work measures not being precisely implemented, endorsing or collecting funds for illegal rare-earth mining activity (including concealment of these activities, secretly allowing them, and participating in illegal rare-earth mining activities).

2) Stringent Admission Threshold and Control of the Granting of Mining Permits: In May of 2010, the Ministry of Industry and Information Technology released A Notice on Publicly Collection Opinions on Rare-Earth Mining Industry Requirements, demarcating a threshold for the rare-earth industry's many targets. In the scope of manufacturing, industrial arts equipment, energy consumption, and integrated resource use, environmental protection, supervising, management, and other fields, the word "notice" establishes regulations[4]. The Jiangxi province should improve its threshold for entrance into the rare-earth industry, strictly implement total control over rare-earth metal mining, and strengthen its right to control mining. Before confirming a certificate, ionic rare-earth metal manufacturing locations must consider at least 3 elements. Does the scope of this mine align with the nationally required target? Do the selected industrial method and technology targets align with the requirements?

3 ) Are the environmental protection facilities complete? Do they strictly prohibit uncertified mining? There should also be strict punishments for those who mine without a certificate, and destroy the natural resource environment and ecology as well as a firm ban of these activities.

\section{B. Strengthening Rareearth Production andExport Management.}

One on hand, Jiangxi must follow the resource dependent enterprise export-related policies, strictly control the rare-earth mining and production amount, plan to consider domestic resources, manufacturing, and consumption, and also the international market condition. On the other hand, Jiangxi must reasonably determine the annual rare-earth export quota, perfect the division of this quota, strictly punish the reselling of one's portion of the quota, elaborate on the rare-earth product tax and border inspection merchandise coding and list rare-earth products in a legal examination catalogue. Furthermore, border inspection should be strictly supervised, the management of the companies' reporting should be standardized, border inspection methods should be perfected, and post-entry rare-earth industry business management should be enhanced to prevent covert rare-earth product exporting. Additionally, the government should firmly crack down on illegal exporting and smuggling of rare-earth products. Border inspection will immediately,with Commercial Affairs and other related departments, develop integration operation dedicated to rare-earth export sequencing, increase document inspections, the strength of inspections, severely punish false reports and false product names as stated in the law, as well as separately handling multi-port "sample product" and "express" illegal rare-earth smuggling activities.

\section{Strengthening Environmental Protection}

If Jiangxi strengthens rare-earth product environmental protection, it must

1) Earnestly implement environmental protection law and improve company leaders', along with the companies in their entirety, awareness of the environment.

2) Strengthen the gathering and transformation of technology, putting "green products" into effect;vigorously spreading the benefits of environmental protection;local industrial technologies [5] that have highresource consumption rates, ammonia nitrogen free metal smelting, linked liquid extraction separation, and other such advanced technologies; accelerating the elimination of reservoir immersion mining, ammonia separation, and other such out-of-date industrial manufacturing lines,

3 ) Develop a cycling economy, increase the recycling and reuse of leftover mining resource and rareearth products, improve the resource recovery ratio and the level of comprehensive resource use, lower the level of energy and product waste, and finally reduce environmental pollution.

Meanwhile, Jiangxi must firmly crack down on actions that harm the ecology and pollute the environment. The environmental protection department must develop integration operations for rare-earth mining and metal smelting and separation companies dedicated to protecting the environment, and stringently carry out national and local pollutant discharge standards. As for construction projects that have not yet been examined by the Environmental Impact Assessment and all discontinued construction projects; a those without pollutant prevention and cure facilities of those with facilities that do not run normally; and companies with abnormally high emissions or companies with recurring emissions that have exceeded the standards on emission control, they are instructed, as according to the law, to immediately cease production, set a time limit for gaining control, and if the mission is not completed within the time limit, their permit will be annulled as according to the law. 


\section{REFERENCE:}

[1] Guozhong Wang The Current Situation of China's Rare-Earth Mining and Development [J] SiChuan Rare Resource 2009(3)

[2] Jianzhong Cheng, Liping Che The Current Situation and trend of China's Rare-Earth Mining and Development [J] April 2010 Volume 31, Period 2.
[3] Pingpeng Ni The Current Situation of China's Rare-Earth Mining and Development of Protective Strgeties. Macroeconomic Research 2010 (10)

[4] Weihong Li Baotou Safeguards Rare-Earth Metals and Creates. The China Mining Industry Newspaper. May 12, 2009. Page C! 